\title{
GORDAILU Y LA RENOVACIÓN PEDAGÓGICA EN EL PAÍS VASCO. POLÍTICA Y EDUCACIÓN EN EL TARDOFRANQUISMO
}

\section{Gordailu and pedagogic renovation in the Basque Country. Politics and education during the late francoism}

\author{
Ander Delgado Cendagortagalarza ${ }^{1}$ \\ Universidad del País Vasco \\ Correo-e: ander.delgado@ehu.es \\ Recepción: 30 de julio de 2015 \\ Envío a informantes: 29 de octubre de 2015 \\ Aceptación definitiva: 23 de febrero de 2016
}

Resumen: En este artículo se analizan las propuestas de renovación educativa y pedagógica situadas en su correspondiente contexto sociopolítico. De este modo se pretende lograr una visión más completa sobre los problemas o facilidades que éstas pueden encontrar cuando se busca su aplicación en los centros educativos. Se considera importante diferenciar en estos proyectos los aspectos relacionados con la gestión del aula de aquellos más generales relacionados con la transformación de la sociedad a través de una educación reformada, que a veces aparecen unidas a este tipo de propuestas, para comprender su recepción social. En este artículo se analizan las propuestas pedagógicas siguiendo los planteamientos de Paulo Freire realizadas en el seno del movimiento de las ikastolas del País Vasco en la década de los setenta del siglo pasado y los problemas que encontraron en su aplicación.

Palabras clave: País Vasco; ikastola; Gordailu; Freire; Franquismo; renovación pedagógica.

Aвstract: This article analyses the educative and pedagogical renovation proposals situated in their social and economic context. Thus, it intends to obtain a wider vision of the problems or helps these proposals may have when it comes to their application in schools. It will be of major consideration to differentiate within these proposals the aspects related with classroom management from other approaches related with the goals

1 Este trabajo se ha realizado en el marco del grupo de investigación del Sistema Universitario Vasco IT-708-I3 y el grupo de investigación del Ministerio de Economía y Competitividad HAR20I4-51956-P. 
to transform the society through a reformed education, that sometimes appear inside them, to understand better their social reception. This article is centred on the research of proposals based on the ideas Paulo Freire tried to introduce in the ikastola or Basque schools in the seventies of the last Century in the Basque Country and the problems they found when their application was intended.

Key words: Basque Country; ikastola; Gordailu; Freire; Francoism; pedagogical renovation.

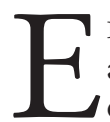
L OBJETIVO DE ESTE ARTículo es ANALIZAR en su contexto social y político algunas propuestas de renovación pedagógica cuya aplicación se planteó en los centros educativos vascos, especialmente en las ikastolas, en los años sesenta y setenta, así como sopesar la incidencia de dicho entorno en su puesta en marcha. Para cumplir con esta finalidad se considera conveniente diferenciar en estas propuestas los aspectos más relacionados con la gestión de aula y del proceso educativo de aquellas metas sociales y políticas de carácter más general que se pretendían conseguir a través de un sistema educativo reformado. Es habitual considerar que los planteamientos pedagógicos pueden servir para cambiar el conjunto de la sociedad a través de la educación proporcionada a los estudiantes en las escuelas. Este último aspecto, cuando se explicita, es el que mayores polémicas puede provocar y terminar dificultando su aplicación. Esta diferenciación permite comprender mejor el papel jugado por el contexto en el proceso de implantación de estas propuestas.

Los últimos años del régimen franquista y los de la Transición fueron años de ebullición social y política, así como de extensión de multitud de propuestas de transformación en diferentes ámbitos, también en la educación. Fue un periodo de abundancia de proyectos y planteamientos educativos presentados en numerosas publicaciones, así como de intentos de grupos de docentes por aplicarlos en los colegios. Por ello, no resulta extraño que el estudio de las propuestas pedagógicas realizadas durante el Franquismo y la Transición sea un tema bastante trabajado. Entre los múltiples acercamientos seguidos en esta cuestión, y sin ánimo de ser exhaustivo, cabe mencionar los estudios sobre los principios educativos del nacional catolicismo franquista (Puelles, 1999; Cámara, 1984) o sobre la aceptación de planteamientos alternativos a los anteriores surgidos en el entorno de las instituciones oficiales a partir de los años cincuenta (Escolano, 1989 y 1992; Pozo y Braster, 2006; Benso, 2006). Mayor atención han atraído, sin embargo, los intentos de modernizar los principios pedagógicos «a pesar» del régimen franquista. El movimiento Rosa Sensat de Cataluña (Codina, 2002), la labor desarrollada por las ikastolas vascas en este mismo sentido (Fernández, 2003; Dávila, 2005a) o los movimientos freinetianos de Madrid y Salamanca (Groves, 20I2) son algunos ejemplos de este tipo de estudios.

Mención especial merecen, para los objetivos de este artículo, los trabajos realizados por Tamar Groves ya que añaden un acercamiento interesante a este campo de estudio. La autora analiza los intentos de renovación pedagógica de las asociaciones Rosa Sensat y Asociación para la Correspondencia y la Imprenta Escolar en el tardofranquismo y la Transición, y los conecta con el proceso de democratización de la sociedad española de aquellos años. Sitúa, por tanto, a la escuela como uno de los agentes que ayudó en ese proceso al socializar a los estudiantes en los nuevos valores 
GORDAILU Y LA RENOVACIÓN PEDAGÓGICA EN EL PAÍS VASCO. POLÍTICA Y EDUCACIÓN EN EL TARDOFRANQUISMO ANDER DELGADO CENDAGORTAGALARZA

democráticos. De este modo, se relaciona al sistema educativo con la sociedad en la que se asienta al presentar los efectos que en ésta puede llegar a producir la primera (Groves, 2012: 307-308).

No cabe duda de que este acercamiento resulta interesante y aporta un campo de reflexión atractivo sobre las relaciones que se establecen entre educación y sociedad. Sin embargo, en este artículo se plantea un acercamiento diferente sobre esta relación, así como al estudio de los proyectos de renovación pedagógica durante el tardofranquismo y la Transición. Para poder conocer mejor su incidencia social es interesante observar, en primer lugar, el contexto social y político en el que éstos se desarrollan y cuáles pueden ser los objetivos pretendidos con su aplicación. En segundo lugar, las dificultades o facilidades que ese contexto pudo establecer para su aplicación y aceptación social. Este último punto resulta de vital importancia para conocer los problemas que su puesta en marcha trajo aparejados, lo que puede aportar interesantes datos para calibrar su incidencia social en un momento tan complejo como fueron los años de cambio de régimen. En definitiva, además de analizar el efecto de los proyectos de renovación pedagógica en la sociedad, también puede ser interesante conocer la incidencia del contexto sociopolítico en la aplicación de estas propuestas.

A pesar de que muchas de las propuestas tenían un componente genérico para todo el sector educativo, otras de las aquí analizadas estaban conectadas con el movimiento de las ikastolas, cuyo proceso de creación de centros se intensificó a partir de los años sesenta ${ }^{2}$. Estas escuelas eran centros de reciente creación donde la aplicación de nuevos proyectos pedagógicos y educativos podía -en teoría- ser más sencilla por no tener que competir con culturas escolares ya asentadas en escuelas que llevaran más tiempo funcionando (Escolano, 2000: 202-203). Esta situación propició el surgimiento de un contexto favorable para la innovación y la creatividad, así como para la aplicación de diversas novedades pedagógicas. No menos importante en el desarrollo de este contexto propicio fue el deseo de los/as fundadores/as de las ikastolas de proporcionar a sus descendientes una educación diferente a la recibida por ellos. Pero al mismo tiempo que este contexto abría estas posibilidades, también creaba toda una serie de limitaciones a su aplicación. La politización de la sociedad vasca de aquellos años de cambio de régimen incidió notablemente en esta situación.

El proceso de creación de estos centros educativos vino acompañado por un gran interés social por la pedagogía y la confianza en su capacidad para influir en la sociedad. Existía una suerte de ilusión pedagógica en el colectivo de docentes y entre sectores sociopolíticos de izquierda y nacionalistas que consideraban a la educación como un medio de transformación social y de construcción de la nueva sociedad vasca a la que muchos aspiraban (Berasain y Haramburu-Altuna, 1975: 47). En ese contexto surgieron diferentes iniciativas de carácter pedagógico o de formación de los docentes en nuevas pedagogías, como fue el caso de la asociación de docentes Gordailu, fundada a finales de los sesenta, cuando el movimiento de las ikastolas estaba adquiriendo cada vez mayor extensión. El colectivo de maestras/os comenzaba a percibir la necesidad de organizarse y coordinarse para desarrollar su trabajo en mejores condiciones. Su aspiración a renovar las prácticas educativas hacía necesario observar otras experiencias

2 Los primeros ejemplos en la fundación de las ikastolas datan de inicios del siglo xx, sin embargo, el origen del actual tejido educativo bajo ese calificativo se inició en los años sesenta. Para más información sobre las ikastolas, sus antecedentes y desarrollo consultar BASURTO (1989), FERNÁNDEZ (I994 y I995), López-Goñi (2003), Dávila (2005b), Movimiento (20II) u Ostolaza (20I2). 
susceptibles de ser utilizadas y analizar las propias para buscar soluciones a los problemas que se hubieran planteado. Así, en 1969, se fundó la asociación Gordailu, uno de cuyos ejes de actuación fue el desarrollo de labores de formación y difusión de cuestiones pedagógicas a través de la organización de cursos, así como elaborar y distribuir material didáctico en euskera para lo que se fundó una editorial. El interés de este grupo estriba en que fue el primer intento de crear una organización dedicada en exclusiva a surtir a las escuelas de materiales educativos en vascuence, principalmente para las ikastolas, superando de ese modo la labor que los docentes desarrollaban individualmente en este ámbito, de ahí su importancia e interés. Destaca también la publicación clandestina de la revista homónima entre los años 1970 y I972, cuya difusión es difícil de determinar, pero cuya influencia en el ámbito, sobre todo, de las ikastolas cabe pensar que fuera significativa, al servir de plataforma de difusión de opiniones, proyectos, aspiraciones, etc., de este grupo de docentes tan implicados en esos centros escolares (Setién, 1979). En ese artículo se analizan las propuestas pedagógicas creadas en torno a la asociación Gordailu y su desarrollo a principios de los años setenta.

\section{Las nuevas pedagogías en las ikastolas}

Las ikastolas fueron uno de los ámbitos donde se intentaron aplicar las novedades pedagógicas que se consideraba que debían caracterizar a una escuela moderna. Muchos docentes estaban especialmente implicados en la defensa de los nuevos caminos que debía discurrir el sistema educativo vasco y no cejaron en su empeño por transformarlo. Partiendo del rechazo de la base autoritaria de la escuela tradicional, desde Gordailu se desarrolló un programa de modernización de las prácticas educativas recurriendo a lo que se denominó, indistintamente, Nueva Pedagogía, Pedagogía Viva o Pedagogía Activa, en la que autores como Freinet, Freire, Montessori, Makarenko... eran mencionados habitualmente (Berasasain y Haramburu-Altuna, I975: 44 y Gordailu, 3, I970: 283).

Estas ideas traían consigo un cambio en la práctica educativa en las aulas. Tomando como referencia la escuela tradicional, la Nueva Pedagogía rechazaba la consideración del alumnado como un elemento pasivo que se limitara a memorizar los contenidos que se le enseñaban. Por el contrario, se buscaba situar al niño/a en el centro del proceso educativo, respetando sus características y personalidad, y promoviendo su aprendizaje a través de metodologías activas (Allur, 1972: 48). Eran las necesidades del niño/a las que se debían intentar satisfacer en las escuelas, así como crear contextos educativos que atrajeran su interés y fomentasen la búsqueda de sus propias respuestas, propiciando así la continuación del proceso educativo. Ése era el modo de conseguir situar al alumnado en el centro del proceso educativo y permitirle dirigirlo y adaptarlo a sus características y necesidades. Para establecer este sistema educativo se debía crear el adecuado clima en el aula que motivara la exteriorización de sus necesidades, dudas, preguntas... (Gordailu, 9, I971: 7-I4).

A estos planteamientos se les añadieron otros no menos interesantes. Se dejó de considerar a la escuela como un lugar aislado y cerrado a su contexto. Se abrió la

\footnotetext{
3 Las citas de los artículos de las revistas se hacen tomando en consideración el número, año de la publicación y página. Dado que muchos artículos son anónimos o con seudónimo -la situación del tardofranquismo así lo requería-, se considera que éste es el mejor modo de evitar unas excesivas referencias bibliográficas.
} 
GORDAILU Y LA RENOVACIÓN PEDAGÓGICA EN EL PAÍS VASCO. POLÍTICA Y EDUCACIÓN EN EL TARDOFRANQUISMO ANDER DELGADO CENDAGORTAGALARZA

escuela a su entorno y éste pasó a formar parte principal de sus actividades buscando, con ello, temas atractivos para el alumnado, más que limitarse a la impartición de unos contenidos sin conexión con su vida diaria (Gordailu, 3, 1970: 7-8). En las ikastolas también se promovieron salidas del alumnado fuera del centro, realizándose no sólo excursiones, sino también estancias de los estudiantes fuera de sus localidades de origen en colonias o udalekus (Fernández, 1994: 155). Para favorecer el aprendizaje significativo, además, se debía recurrir a actividades prácticas que promovieran la capacidad de pensamiento en el alumno/a, de análisis crítico de la realidad social, además de acostumbrarlos al diálogo, la creatividad y a la toma de decisiones en libertad (Gordailu, 3, 1970: 29).

Los planteamientos que someramente se han presentado pueden considerarse como asumidos con naturalidad en la pedagogía y didáctica de la actualidad, sin embargo, su aplicación en la época objeto de estudio no estuvo exenta de problemas ni su puesta en marcha fue inmediata. Los propios integrantes de la asociación Gordailu (IO, I97I: I8) reconocían que aún se encontraban dando los primero pasos en el sentido apuntado, siendo aún una tendencia marginal y una pedagogía de oposición al modelo imperante. Pero para entender las dificultades con las que se encontró en su aplicación hay que analizar otro aspecto. Para muchos de los defensores de esta nueva pedagogía su propuesta no debía limitarse a ser una técnica de gestión del aula. Su objetivo era otro: transformar la sociedad (Gordailu, 4, I970: 24). Y dado que ambos aspectos formaban parte de su proyecto renovador, las disputas en torno a este último elemento afectaron a la aplicación de las prácticas de gestión del aula mencionadas más arriba.

En la documentación utilizada aparece reflejada claramente esta finalidad de transformación social. Esta visión era deudora, en gran parte, de los planteamientos del pedagogo brasileño Paulo Freire, especialmente los de su obra La educación como práctica de la libertad, publicada en 1968. Las ideas de Freire fueron muy influyentes en la España de principios de los setenta, como ha analizado Tamar Groves (20IIa). Este autor consideraba que la pedagogía no era una actividad neutra o una mera serie de técnicas de uso en las aulas para conseguir un mejor aprendizaje del alumnado. La pedagogía, en cuanto forma de organizar el proceso educativo, era un mecanismo con importante influencia social que se podía manifestar de dos formas. Por un lado, reproduciendo y cimentando el orden social existente. Por otro lado, transformando ese orden y creando otro nuevo con características diferentes. En ese sentido, no existía la posibilidad de ninguna educación neutra o apolítica. Se consideraba innegable que cualquier educación estaba íntimamente unida a una opción política y sostenimiento de un sistema político y económico determinado (Gordailu, Io, I971: 4).

En un artículo de Luis Haramburu-Altuna (197I) con el título de «Pedagogia askatzailea» [«edagogía liberadora»] se mencionaba esta opción al afirmar que cualquier pedagogía tomaba el aspecto del modelo social en el que se desarrollaba y defendía. Ante esa situación, la pedagogía que se estaba intentando desarrollar en las ikastolas se podría denominar «liberadora» en la medida que su objetivo era crear estudiantes críticos, con capacidad de pensar y hacer frente a las situaciones que les tocase vivir. En definitiva, como afirmaba este autor en otro texto posterior, se debía acercar a los estudiantes a las contradicciones de la sociedad en la que vivían y capacitarlos para luchar contra ellas. Ello propiciaría la desaparición de las contradicciones económicas y políticas en el futuro y sólo de esa forma se conseguiría cambiar el sistema social (Haramburu-Altuna, 1972: 172). 
¿Cuál era el orden social al que se debía hacer frente? El capitalismo. Un capitalismo que convertía al ser humano en materialista, individualista, consumista, conformista... utilizando una de sus herramientas más importantes para ello: la educación. El objetivo de las ikastolas -según opinión del anónimo autor de otro artículo- debía ser crear un «hombre revolucionario» que se situase al lado de los oprimidos y los trabajadores y luchase por sus derechos (Gordailu, 5, I97I: I4-15). Para ello era necesario educar a los estudiantes sobre las características de la sociedad que les había tocado vivir, la explotación de los trabajadores y sus consecuencias y prepararles, en definitiva, para cambiar esa sociedad. Así, según esta visión, al trabajador del futuro solo le cabían dos opciones: aceptar su explotación o ser consciente de ésta y luchar en el campo de los trabajadores (Gordailu, 6, 1971: 7). ¿Cuál era el objetivo que debía perseguir esa lucha? El socialismo. Este objetivo aparece explicitado en dos ocasiones -por lo menos- en la revista Gordailu y en ambas ocasiones se considera que la educación debía ayudar en recorrer ese camino. Por tanto, desde esta perspectiva, la función de las ikastolas no era solo defender y promover el euskera en la sociedad vasca, su función era liberar a los vascos para conocer su verdadera identidad y situación. Para ello era necesario dar inicio a la escuela «proletaria» (Gordailu, II, 1972: I4).

\section{Dificultades de implantación}

El intento de aplicación de un proyecto pedagógico como el que se acaba de presentar no estuvo exento de problemas. Su objetivo trascendía el ámbito de las meras técnicas de enseñanza para el aula y tenía como finalidad transformar la sociedad en una dirección que se podía calificar como revolucionaria. Un planteamiento de ese tipo no encontró el apoyo de todos los sectores sociales y políticos implicados en las ikastolas. El ámbito de las fuerzas políticas antifranquistas era heterogéneo y no todas estaban de acuerdo con planteamientos de ese tipo. Por ello, resulta lógico que el intento de aplicarlas provocara, en ocasiones, problemas y enfrentamientos entre los integrantes de las ikastolas, más aún en un contexto tan politizado como el de los años setenta en el País Vasco.

Para comprender esta circunstancia hay que prestar atención al proceso de creación y a los apoyos sociopolíticos de las ikastolas. Los sectores políticos que en sus inicios se encontraban detrás de este movimiento se pueden situar en el ámbito de un genérico «vasquismo» en el que el PNV ocupaba una posición predominante, lógica por su propia extensión social y organización, aunque no era la única sensibilidad existente entre los fundadores de las ikastolas (Movimiento: 20II, 47-48; Arredondo, 2003: 2I). Bien fuera en calidad de militantes o de simples simpatizantes de esos planteamientos, se puede afirmar que muchos de sus impulsores se encontraban en el entorno político nacionalista vasco preocupado por la crisis cultural y lingüística que muchos percibían en aquellos años. Habitualmente se ha caracterizado a este sector como conservador y católico, como parecía indicar la intensa implicación de parte del clero en esta iniciativa educativa.

Esta situación fue cambiando desde mediados de los años sesenta en adelante. Un sector de la juventud influido por el pensamiento marxista comenzó a dejar patente su desengaño con la actividad y las estrategias de los partidos republicanos «clásicos» -el PNV entre ellos- y empezó a desarrollar planteamientos más progresistas influenciados 
GORDAILU Y LA RENOVACIÓN PEDAGÓGICA EN EL PAÍS VASCO. POLÍTICA Y EDUCACIÓN EN EL TARDOFRANQUISMO ANDER DELGADO CENDAGORTAGALARZA

por el marxismo y nuevas formas de militancia y organización política, que en el País Vasco tuvo a ETA como uno de sus referentes, aunque no el único. Esta juventud con ideas diferentes a las tradicionales del nacionalismo vasco también hizo acto de presencia en las ikastolas a través de muchos docentes, familias y socios colaboradores. Estos planteamientos de carácter progresista se manifestaban, por ejemplo, en la cercanía a las modernas pedagogías antes mencionadas de muchos docentes de las ikastolas (Anaitasuna, 258, 31.07.1973: 3).

Esta circunstancia supuso el inicio de una pugna entre estos dos mundos del nacionalismo vasco que también se dejó sentir en el seno de las ikastolas. Sus integrantes más movilizados e implicados políticamente, como era el caso de muchos docentes, presentaron sus ideas y visiones políticas en las asambleas de los centros educativos cuando se tenían que tomar decisiones que podían ser controvertidas. Y aunque pudieran existir intenciones de controlar estas escuelas, como se mencionaba en algún artículo de prensa (Anaitasuna, 245, I5.I2.1972: 9), estas disputas no se materializaron -hasta donde se conoce- en dependencia orgánica de ninguna organización política. Más bien, se trató de hacer prevalecer las opiniones de cada uno de los colectivos implicados en la gestión y funcionamiento de las ikastolas, o intentar atraer a sus integrantes a los postulados defendidos en cada uno de los entornos políticos (Errezabal, 1974: I). Más difícil resulta determinar, con el nivel de conocimientos con el que se cuenta, en qué se podían manifestar estas diferencias en el ámbito de la gestión de las aulas y la práctica educativa diaria. ¿Quizás se limitó a decidir, por ejemplo, sobre la presencia o no de la religión, mientras las nuevas pedagogías y didácticas aplicadas en el aula quedaban al margen del debate o se extendían paulatinamente? Estas diferentes opiniones, en todo caso, salían a relucir cuando se debía decidir sobre aspectos como la aplicación de las ideas de la moderna pedagogía o cuando los objetivos más maximalistas antes mencionados debían materializarse en aspectos concretos relativos a la organización y vida diaria de los centros escolares.

Los debates existentes en muchos centros se desarrollaban en torno a una interrogante: quién debía dirigir estos centros o, en otras palabras, Ikastolak norenak diren [de quién son las ikastolas] (Anaitasuna, 257, 30.06.1973: 3). Para muchos, además del derecho inherente de las familias para decidir sobre la educación de sus hijos/as, pesaba el hecho de que los centros se habían convertido en cooperativas de padres y madres y, en consecuencia, a éstos les correspondía determinar las características del centro y qué contenidos se enseñaban en los mismos (Delgado, 20I4). En definitiva, las ikastolas debían considerarse como escuelas privadas a todos los efectos, correspondiendo, por tanto, a sus impulsores decidir sobre su funcionamiento. Aquellos/ as que no aceptasen dichas características mayoritariamente aprobadas tenían la oportunidad de crear su propio centro con las que considerasen oportunas (Lasa, I97I: I84-I86).

Otro sector defendía, por el contrario, el carácter popular de estas escuelas. Habían surgido en la década anterior gracias al esfuerzo del «pueblo»y, por ello, debían ser escuelas "populares» donde, además de los padres y madres, pudieran participar en su dirección los trabajadores, los colaboradores, los/as maestros/as y otros sectores interesados. Siendo tan importante el papel atribuido a estas escuelas, su labor no podía quedar en manos exclusivas de un determinado sector social representado por determinadas familias, por muy directamente concernidas que pudieran estar en su desarrollo. De convertirse en escuelas privadas de pago al uso, 
esa circunstancia iba a reducir su incidencia social a los colectivos con una posición económica que les permitiera pagar las correspondientes cuotas. Ello las convertiría en escuelas «burguesas».

Siendo tan contrapuestas las visiones existentes sobre las ikastolas resulta lógico suponer que cuando se tenía que decidir sobre temas controvertidos las diferencias salieran a relucir. En esos momentos surgían los debates internos y las discrepancias, que algunas veces daban lugar a la confrontación y, a veces, a la división en el seno de las ikastolas. Situación que, en algunas ocasiones, se desarrollaba en el ámbito del enfrentamiento personal, lo que convertía estas divergencias en agrias disputas. Los temas que dieron lugar a este tipo de enfrentamientos fueron, básicamente, el papel de la religión y el ateísmo en estas escuelas y, en menor medida, diferencias sobre cuestiones pedagógicas, todo ello aderezado, en algunas ocasiones, con ácidas referencias a la vida privada de los maestros/as. Aspectos, en definitiva, que tenían su origen en las diferencias políticas e ideológicas de los integrantes de las ikastolas (Garín, 1978).

La presencia o no de la religión entre los contenidos a impartir en estos centros fue el tema principal de debate en las ikastolas desde finales de los años sesenta. Para muchos era evidente que la sociedad vasca estaba en proceso de cambio y uno de los ámbitos donde con más intensidad se constataba éste era en la pérdida de importancia de la religión y en el crecimiento de los sectores sociales laicos influenciados por el pensamiento marxista de la época (Lasa, I97I: II6). Ello suponía una fractura en la tradicional visión que unía al pueblo vasco con la religión católica -idea reflejada en el tradicional lema de euskaldun fededun o vasco creyente- que, a pesar de todo, aún mantenía vigencia en la sociedad vasca. Por ello, la solución que se le diera a la demanda de la Iglesia vasca y de parte de las familias al mantenimiento de la religión en las escuelas no era sencilla, toda vez que reflejaba la disputa de dos visiones diferenciadas sobre cómo debía ser la sociedad vasca: religiosa o laica y toda la gradación que iba entre ambos extremos.

No en todos los centros se dio la misma solución a este tema, dado que en algunos se integró la religión entre sus contenidos curriculares, mientras otros dejaron en manos de la catequesis parroquial la enseñanza de la doctrina cristiana para aquellas familias que lo demandaran. En algunos centros, sin embargo, no se pudo llegar a ningún acuerdo y la ikastola se dividió. En el estudio realizado por Gregorio Arrien (1993) sobre las ikastolas de Bizkaia entre los años 1957 y 1972 se observa la incidencia de este tipo de polémicas: de los dieciséis centros de esta provincia cuyo desarrollo analiza, en seis hubo conflictos internos de diferente intensidad que provocaron su división. En la década de los sesenta esta posibilidad parecía impensable por el grado de implicación, militancia y colaboración existente entre todos los elementos implicados en el desarrollo de los centros. Sin embargo, en la siguiente década y a medida que las ikastolas iban regularizando su situación, los debates internos terminaron por afectar a las relaciones internas de los centros, manifestándose, en algunas ocasiones, a través de despidos.

Uno de los ejemplos lo vivió Eusebio Osa, destacado educador integrante de Gordailu. En 1971 se encontraba trabajando en la ikastola de Vitoria y fue despedido del centro. Según la revista Gordailu (I0, I97I: 4I-45) y su viuda (Elustondo, 2005: 17), la junta de padres y madres le acusó de intentar introducir el marxismo y el ateísmo en el centro. Poco después, a finales de ese año, Osa optó al cargo de director y asesor pedagógico de las ikastolas del entorno de Arrasate (Mondragón), foco del movimiento 
GORDAILU Y LA RENOVACIÓN PEDAGÓGICA EN EL PAÍS VASCO. POLÍTICA Y EDUCACIÓN EN EL TARDOFRANQUISMO ANDER DELGADO CENDAGORTAGALARZA

cooperativo vasco. Aunque se carece de muchos datos, las fuentes utilizadas indican que la junta de padres y madres de esa localidad no estaba de acuerdo con su nombramiento, mientras los maestros/as lo consideraban el candidato más adecuado. En las noticias sobre el caso se hacía referencia a que habían llegado informes negativos sobre Osa desde Vitoria y de que algunos sectores del cooperativismo local -en el que el elemento católico tenía mucha importancia- tampoco estaban dispuestos a aceptar su nombramiento. Y, no menos significativo, de que la junta de padres y madres quería establecer una educación donde la religión estuviera presente. Datos que indican que en esta ocasión también existían las mismas o similares razones que las mencionadas anteriormente. La negativa de la junta tuvo como consecuencia el rechazo de muchos maestros/as a esta decisión y su posicionamiento en contra de dicha junta, lo que terminó provocando el despido de quince de ellos/as (Gordailu, I8, 1972: 23 y 32-36; Anaitasuna, 246, 30.12.1972: 8-9). A estos despidos se unieron, entre 1971 y 1972, otros más por razones similares en otras localidades vascas, así como otros abandonos supuestamente forzados por la situación que tenían que padecer muchos docentes en algunos centros (Berasain y Haramburu-Altuna, 1975: 45).

\section{Más divisiones}

La pugna existente en el entorno de las ikastolas durante los años setenta no se limitó a la apuntada hasta aquí. Hubo un segundo elemento que también dificultó notablemente que la propuesta de renovación pedagógica aquí presentada terminara por cuajar, aunque muchos de los aspectos relativos a la gestión del aula mencionados consiguieran aplicarse paulatinamente. En el nuevo movimiento nacionalista vasco influenciado por el marxismo tampoco se daba una situación homogénea. La aparente unidad que había mostrado este entorno político comenzó a resquebrajarse en los años setenta. De una forma sintética se puede describir este proceso como la pugna de los dos ejes del discurso que caracterizó a este movimiento político: el obrerismo internacionalista o el nacionalismo vasco. El mejor ejemplo de esta situación se constata en el desarrollo de ETA, especialmente, desde su vi Asamblea (1970) en adelante y en todas las escisiones a las que dio lugar. Una línea de esta organización terminó después de varias vicisitudes en la posterior ETA militar de carácter nacionalista y otra en diferentes partidos o grupos de carácter maoísta, trotskista o comunista. Pero lo importante de estos conflictos no es solo que se redujeran al ámbito de la militancia política más activa, sino que fue un debate que impregnó todo el entorno político juvenil nacionalista vasco y dejó sentir sus efectos en amplias capas sociales. Un proyecto de renovación pedagógica tan influenciado por el pensamiento marxista no pudo mantenerse ajeno a esta polémica.

Respecto a este tema resulta más difícil lograr información, pero hay algunos datos que indican que esta polémica también llegó, por lo menos para el año 1972, al ámbito de las ikastolas. Y se puede proponer que trajo consigo una fractura más en el colectivo de maestros/as, así como en Gordailu, lo que redujo el apoyo a los planteamientos pedagógicos analizados y provocó que la actuación conjunta de inicio de los años setenta terminara por diluirse por las diferencias políticas citadas. Eusebio Osa reconocía que en aquellos años tanto él como los que se movían en torno suyo consideraban que el problema nacional iba a ir perdiendo fuerza siendo la lucha de 
clases el aspecto que iba a adquirir más relevancia, visión que enlaza directamente con el debate mencionado. De hecho, Eusebio Osa comentaba en una entrevista, sin especificar cuándo, que diferentes sectores comenzaron a acusarle de marxista y «españolista $»^{4}$ (Zubiondo y Mollarri, I983). Circunstancia que se vería confirmada por el acercamiento de Osa a la Organización de Izquierda Comunista (OIC/EKE) a finales de los setenta (Sudupe, 20I4: IO6). Una maestra despedida de la ikastola de Arrasate en 1972 a consecuencia de los acontecimientos antes descritos también reflejaba la división surgida en el seno del movimiento de docentes y su entorno. Si en un principio consiguieron concitar el apoyo de gente de diferentes ideologías, poco después comenzaron a llamarles «comunistas» o «españolistas» y reduciéndose las muestras de apoyo a sus reivindicaciones ${ }^{5}$. La consecuencia de estos debates también los mencionaban claramente tres de los integrantes de Gordailu en una entrevista realizada en 1982: al no declararse algunos de sus integrantes como nacionalistas se acusó a todo el grupo de «españolistas» y a consecuencia de la «intolerancia» de aquellos años comenzó su «marginación» (J. I., 1982).

El conflicto entre nacionalismo conservador y progresista y entre las dos corrientes en este segundo grupo provocaron la división en el entorno de estas iniciativas educativas en un momento de intensa politización y radicalización en la sociedad vasca. Esta circunstancia era considerada por muchos como un riesgo para todo el movimiento porque la división podía traer la desaparición de las ikastolas. Éstas, como el resto de la sociedad, también estaban llenas de contradicciones y hacían acto de presencia muchas ideas y debates del ámbito político vasco. Por ello, no resulta extraño que comenzaran a escucharse cada vez más voces que buscaban dar una salida a esa situación, que, en general, se consideraba que debía transitar por abandonar los maximalismos políticos y reforzar la labor de defensa de la cultura y lengua vascas; en cuya defensa, a priori, todos estaban de acuerdo. En enero de 1973 un redactor escondido bajo el seudónimo de Abarka afirmaba que las divisiones políticas podín terminar por ahogar a las ikastolas y, aunque el apoliticismo no podía ser exigido a sus integrantes, los intereses específicos de cada uno sí se podían dejar aparcados para trabajar unidos en favor de la educación en euskera, verdadera lucha de estos centros. Traer a las ikastolas una posible lucha de clases entre maestros/as y las familias sería un error que solo ayudaría a dividir y debilitar a los centros escolares (Anaitasuna, 247, 15.01.1973: 3).

Pero las soluciones propuestas ante la división existente en las ikastolas no se limitaron a propugnar esta colaboración dejando de lado las propuestas políticas de cada uno. También se realizó una crítica profunda a los planteamientos que desde una óptica marxista radical se estaban defendiendo en el movimiento de las ikastolas, lo que redundó, aún más, en un rechazo a los planteamientos analizados. En un artículo de la revista Zabal, publicada en Bayona, de principios de 1974 se realizó un análisis de conjunto de la situación de estos centros escolares (Errezabal, 1974). El autor partía de la base de que en estos centros educativos se reflejaban todas las pugnas y contradicciones políticas existentes en la sociedad vasca. Pero su análisis no ponía en igualdad de condiciones todas las iniciativas que se estaban planteando en torno a ellas, ni

4 Este calificativo se debía a que los seguidores de esta opción terminaron por enfatizar los problemas de la clase trabajadora, cuyos problemas y soluciones superaban las fronteras del País Vasco, frente a la nación.

5 Información recuperada el 6 de noviembre de 2015, de http://sustatu.eus/goioarana/I355132240. 
GORDAILU Y LA RENOVACIÓN PEDAGÓGICA EN EL PAÍS VASCO. POLÍTICA Y EDUCACIÓN EN EL TARDOFRANQUISMO ANDER DELGADO CENDAGORTAGALARZA

se limitaba a defender un supuesto apoliticismo para las ikastolas. Consideraba que algunos sectores actuaban a favor de éstas, mientras otros lo hacían en su contra. Entre los primeros situaba a los «sectores pequeño burgueses conservadores»-léase, el PNV con ayuda de la Iglesia- que buscaban imponer sus visiones en los centros pero defendiendo en todo momento la viabilidad de los centros y su función de defensa de la lengua y la cultura vascas 6 . Sin embargo, el autor destacaba otra corriente, a la que denominaba como ezkertikerizkoa o izquierdismo, que también estaba presente en las ikastolas, pero que debido a su pensamiento no favorecía su mantenimiento, más bien su desaparición, siempre que no se adaptasen a sus planteamientos marxistas radicales. Si en opinión de este sector la verdadera liberación de la sociedad vasca pasaba por acabar con la burguesía y establecer la sociedad socialista. Y, también según esta visión, si las ikastolas se convertían en escuelas burguesas, como parecían indicar las pugnas existentes en los centros y los autores aquí analizados no se cansaban de repetir, el desarrollo lógico de su planteamiento marxista radical era que podía ser mejor su desaparición. Esa era la forma de impedir la socialización y mantenimiento de los principios de la sociedad burguesa derivada de una praxis educativa anclada en esos valores. A ello añadían que si en las escuelas públicas también había maestros/as que defendían los planteamientos marxistas y estaban matriculados más hijos/as de trabajadores que en las ikastolas por su carácter gratuito, quizás la solución preferible sería intentar transformar las escuelas públicas para socializar a más estudiantes en otros principios. En definitiva, según el autor de este análisis de la situación de las ikastolas, esta corriente de opinión partía de la contradicción interna de estos centros educativos para absolutizar ese enfrentamiento y llegar hasta defender su desaparición, siempre que esos centros no se transformaran de arriba abajo.

Estos planteamientos marxistas llevados a su último extremo los hizo públicos ETA en 1973, en seno de los debates de su vi Asamblea, en su segunda parte, al utilizar el argumento del lenguaje popular y el de la clase dominante, además de la idea de lengua impuesta frente a la del «pueblo». Y en su análisis, la situación de las ikastolas no era más que una «segregación» del análisis general aplicado a las escuelas públicas, dado que servían a los mismos intereses de las clases dominantes burguesas. Característica acentuada por su carácter de escuela de pago. Por tanto, las reivindicaciones para las ikastolas eran las mismas que para el conjunto del sector educativo, de las que no las diferenciaba y entre las cuales las diluía en cierta forma. De hecho, defendía la unión de todos los maestros/as de las ikastolas y las públicas en un programa reivindicativo común, además de propugnar la enseñanza laica y popular para todos los centros, la subvención del Estado a las ikastolas, lo que las convertiría en centros públicos a todos los efectos, etc. ${ }^{7}$.

Este discurso lo rechazaba el autor/a del artículo de Zabal y proponía otro esquema de interpretación de las ikastolas, que superaba el análisis marxista presentado y proporcionaba un papel a estos centros educativos en la sociedad vasca del momento. Porque su labor no se limitaba a enseñar el euskera; de hecho, el propio régimen franquista estaba dando cierto espacio -más retórico que práctico- a este idioma a través del articulado de la Ley General de Educación de 1970. Las ikastolas desempeñaban otra función que las escuelas públicas, en cuanto correa de transmisión de las políticas

6 Lo cual no impedía, en opinión del autor, que las ikastolas, a pesar del control ejercido por este entorno político, fueran mucho más avanzadas que en cualquier otro momento anterior.

7 Zutik!, 55, marzo 1973. Reproducido en Documentos Y, vol. 13. San Sebastián: Hordago, 1981. 
GORDAILU Y LA RENOVACIÓN PEDAGÓGICA EN EL PAÍS VASCO.

POLÍTICA Y EDUCACIÓN EN EL TARDOFRANQUISMO

ANDER DELGADO CENDAGORTAGALARZA

estatales, nunca cumplirían. Porque el verdadero análisis de la situación de la época, según su enfoque y sin negar la validez de la contradicción de clase tantas veces mencionada, era otro: los Estados español y francés oprimían al pueblo vasco. Por ello,

Hizkuntza atzerritarren menpean zapalduta galbidean aurkitzen den une hontan, iraultzaile batentzat lehenengo eginkizuna nazio hizkuntzaren alde burrukatzea dela zapaltzaile guztien aurka, eta ez gure artean $[\ldots]^{8}$.

En definitiva, las ikastolas eran los frutos de la lucha del pueblo vasco por su libertad y eran consideradas las iniciativas más importantes desde 1936 en defensa de la lengua y cultura vascas. Por tanto, en vez de ser criticadas y buscar enemigos internos, debían ser apoyadas y reforzadas por todos en su lucha contra la opresión nacional e idiomática, para lo cual era necesario que contaran con total autonomía en el seno de la lucha popular. Se debían rechazar, por tanto, las teorías izquierdistas, calificadas como de «moda», que determinaban la práctica de estos centros más allá de la problemática de la opresión nacional e idiomática del pueblo vasco (Errezabal, 1974).

\section{Conclusiones}

El objetivo de este artículo ha sido profundizar en las razones por las que determinadas reformas y proyectos pedagógicos encuentran problemas y dificultades cuando se pretende su aplicación en el ámbito educativo. Para comprender las circunstancias vividas por estas propuestas resulta insuficiente limitarse al estudio de las características de las mismas. Esta labor -necesaria, sin duda- no aporta la suficiente información para comprender las razones por las que un determinado proyecto pedagógico, que en el plano teórico pudiera contar con argumentaciones bien sustentadas, en el momento de su aplicación encuentra el rechazo de parte de los agentes educativos. Para profundizar en este tema se ha considerado conveniente situar estos proyectos y sus intentos de aplicación en su correspondiente contexto social y político. Esta contextualización resulta un factor de primer orden para comprender sus facilidades o dificultades en el momento de su puesta en marcha, su mayor o menor recepción social, etc.

El análisis del proyecto de renovación pedagógica cuya puesta en marcha se intentó en el movimiento de las ikastolas de los años setenta resulta un ejemplo interesante para profundizar en este aspecto. Las prácticas propuestas para la gestión de aulas muestran su carácter transformador e innovador. Propuestas que hoy en día están relativamente asumidas, pero que en aquellos años suponían un gran salto respecto de la educación mayoritariamente imperante en el régimen franquista y que encontraron en el ámbito de las ikastolas un entorno adecuado para su aplicación. Pero también es evidente que el marcado carácter marxista de los impulsores de estas propuestas provocó que su puesta en marcha encontrara dificultades. Dado que la reforma de la gestión del aula y la transformación de la sociedad en una dirección revolucionaria eran dos caras de la misma moneda, el primer aspecto pudo sufrir los efectos del

8 «Cuando en este momento el idioma se encuentra oprimido y en peligro de desaparecer en manos de los extranjeros, la primera labor para un revolucionario es luchar por el idioma nacional contra todos los opresores, y no entre nosotros» [Traducción del autor] (ERREZABAL, I974: vii). 
GORDAILU Y LA RENOVACIÓN PEDAGÓGICA EN EL PAÍS VASCO. POLÍTICA Y EDUCACIÓN EN EL TARDOFRANQUISMO ANDER DELGADO CENDAGORTAGALARZA

radicalismo del segundo, aunque paulatinamente esas prácticas consiguieran ir aplicándose. Y, todo ello, a pesar de que durante los años sesenta y, especialmente, los setenta el marxismo, unido al nacionalismo, adquirió gran predicamento en la sociedad vasca. Sin embargo, también resulta evidente que no todos - ni siquiera el conjunto del entorno nacionalista vasco- estaban de acuerdo con este tipo de planteamientos marcadamente marxistas. Las propuestas maximalistas y el análisis dogmáticamente marxista no encontró la respuesta adecuada en el ámbito educativo. La propia politización social y radicalización política en múltiples direcciones de la sociedad vasca de los años setenta no fue el mejor contexto para un proyecto políticamente tan alineado. Aunque la politización, habitualmente, se ha situado en el ámbito del nacionalismo vasco de izquierdas, los intentos de aplicación de la propuesta pedagógica analizada muestran que otros sectores políticos, menos destacados en este aspecto, también estaban presentes y contaban con la capacidad suficiente para hacer frente a propuestas como las analizadas.

La situación analizada responde a unas características específicas de un movimiento educativo concreto y a un contexto sociopolítico determinado. La intensa movilización política de la sociedad vasca de los años setenta son específicas y difícilmente extrapolables, ni siquiera extensibles a momentos posteriores en el mismo País Vasco. A pesar de ello, del análisis realizado se pueden apuntar dos aspectos de carácter más general interesantes a tomar en consideración.

En primer lugar, se ha podido observar que al margen del colectivo de docentes militantemente implicados en este proyecto y en la temática pedagógica, la respuesta de las familias a las mismas fue relativamente fría. No todas las familias veían con agrado este tipo de «experimentos» con sus descendientes. Como los propios integrantes de Gordailu (3, I970: 5; 9, I97I: II-I4; IO, I97I: 45) manifestaban en sus textos, muchas familias tenían como objetivo que sus hijos/as lograran unas buenas calificaciones en sus exámenes que les permitieran concluir sus estudios en buenas condiciones y les permitieran el mejor futuro laboral y el mayor ascenso social posible, además de su interés por el euskera y/o la educación religiosa ${ }^{9}$. Lo que trae a colación la contradicción existente, en muchas ocasiones, entre el colectivo docente más implicado, militante y defensor de la capacidad de transformación social de la educación, frente a la percepción o interés social sobre sus propuestas. Aunque algunas propuestas pedagógicas puedan ser consideradas positivas y progresistas, en determinados momentos no todo el mundo tiene por qué verlo con buenos ojos. O, quizás, muchas familias veían en la educación un elemento clave de ascenso social o camino de mejora de las futuras condiciones económicas y laborales de sus descendientes, más que una forma de transformar la sociedad.

En segundo lugar, parece más significativo otro aspecto íntimamente unido a propuestas pedagógicas como las analizadas. Se trata de la diferencia existente entre las propuestas de gestión interna del aula o de los centros educativos, frente a las propuestas de índole más general que buscan la transformación social a través de una educación diferente y renovada. Es decir, la diferencia que se establece entre los nuevos planteamientos a aplicar en las aulas frente a otros proyectos para el conjunto de la sociedad o, como en el caso analizado, de un carácter maximalista y marcadamente

9 Esta situación no era exclusiva del País Vasco. En Salamanca, durante la Transición, se observa un proceso similar ante las prácticas educativas que los maestros rurales intentaban establecer (Groves, 20Irb: I42). 
GORDAILU Y LA RENOVACIÓN PEDAGÓGICA EN EL PAÍS VASCO.

POLÍTICA Y EDUCACIÓN EN EL TARDOFRANQUISMO

ANDER DELGADO CENDAGORTAGALARZA

marxista. Como se ha podido observar en este trabajo, las ideas referidas al primer grupo hoy en día son normalmente aceptados entre docentes y familias ${ }^{10}$. Sin embargo, los planteamientos que desde el ámbito de la pedagogía se realizan para transformar la sociedad a través de la educación pueden encontrar la resistencia de familias y determinados sectores políticos. Más aún cuando esos objetivos se presentan con una marcada identificación política que puede llegar a chocar con las diferentes sensibilidades políticas de un determinado momento. $\mathrm{O}$, cuando se basan en un análisis radical de la realidad educativa, pueden tropezar con la amplia implicación social en un proyecto como el de las ikastolas, que requirió de la intensa movilización de muchos/ as para sacar adelante un proyecto de educación en euskera en los años finales del Franquismo. Circunstancia que obliga a tener en cuenta la relación que se establece en estos proyectos entre las propuestas para el aula y las genéricas de cambio social para así poder comprender el mayor o menos rechazo existente a las mismas.

\section{Bibliografía}

Allur, A. (1972) Ikastolak eta Irakasleak. Jakin Sorta, 6, 47-54.

Aranburu, P. J. (2015) Jaxinto, ikastolen lemazaina (Hiazinto Fernandorena Setien). San Sebastián, s. n.

Arredondo, J. (2003) Asti Leku Ikastola 1963-2003. 40 aniversario. Portugalete: Asti Leku.

Arrien, G. (1993) Las Ikastolas de Bizkaia, 1957-I972: sus orígenes y organización. Cuadernos de Sección. Educación, 6, I5-277.

BAsURTO, F. (1989) La normalización de la ikastola: breve historia y estado de la cuestión de la Escuela Pública Vasca. Historia de la Educación, 8, I39-165.

Benso, C. (2006) Tradition and innovation in the practical culture of schools in Franco's Spain. Paedagogica Historica, 42 (3), 405-430.

Berasain, M. y Haramburu-Altuna, L. (1975) Ikastola (Colegio de pago o escuela popular). Triunfo, 655, 42-47.

Cámara, G. (1984) Nacional-Catolicismo y escuela. La socialización política del Franquismo (1936-I95I). Jaén: Hesperia.

Codina, M. T. (2002) Rosa Sensat y los orígenes de los movimientos de renovación pedagógica. Historia de la Educación, 2I, 9I-IO4.

DÁvila, P. (2005a) La renovación pedagógica en el País Vasco (segunda mitad del siglo xx). Sarmiento, 9, 85-103.

DÁvila, P. (2005b) The Educational System and National Identities: the Case of Spain in the Twentieth Century. History of Education, 34 (I), 23-40.

Delgado, A. (2014) Co-operatives and education in the Basque Country. The ikastolas in the final years of Franco's dictatorship. History of Education, 43 (5), 676-69o.

Elustondo, M. A. (2005) Eusebio Osa (1936-1993) (col. Bidegileak). Bilbao: Gobierno Vasco.

Errezabal (1974) Ikastolak hego aldean. Zabal (Baiona), 5, enero/febrero.

Escolano, A. (1989) Discurso ideológico, modernización técnica y pedagogía crítica durante el Franquismo. Historia de la Educación, 8, 7-27.

10 Aun así y aunque sea en el ámbito de los rumores más o menos extendidos en aquella sociedad vasca de los años setenta -difíciles de documentar, por tanto-, cuando se habla de este tema con algunos de los participantes en el movimiento de las ikastolas es posible escuchar referencias sobre que en aquellos años se rumoreaba que se impartía educación sexual a los niños/as, que los estudiantes estaban desnudos en clase, etc. Datos que hablan de la percepción errónea de parte de la sociedad de los pasos que se estaban dando en las ikastolas y del choque que pudo suponer el intento de modernizar la educación que comenzaba a salir del Franquismo. Aun así, estos rumores no parecen desacreditar la idea defendida más arriba. 
GORDAILU Y LA RENOVACIÓN PEDAGÓGICA EN EL PAÍS VASCO.

POLÍTICA Y EDUCACIÓN EN EL TARDOFRANQUISMO

ANDER DELGADO CENDAGORTAGALARZA

Escolano, A. (1992) Los comienzos de la modernización pedagógica en el franquismo (I95I1964). Revista Española de Pedagogía, 192, 289-310.

Escolano, A. (2000) Las culturas escolares del siglo xx: Encuentros y desencuentros. Revista de Educación, n. ${ }^{\circ}$ extr. I, 20I-2I8.

FERNÁNDEZ, I. (1994) Oroimenaren hitza. Ikastolen historia I960-1975. Bilbao: UEU.

Fernández, I. (I995) La escuela vasca y la larga historia de la posguerra. En P. DÁvila (coord.) Lengua, escuela y cultura. El proceso de alfabetización en Euskal Herria, siglos XIX y XX (pp. I59-I9I). Bilbao: UPV.

Fernández, I. (2003) La renovación pedagógica en el País Vasco. En P. DÁvila (coord.) Enseñanza y educación en el País Vasco contemporáneo (pp. 79-95). San Sebastián: Erein.

GARín (1978) Las ikastolas como indicador de un pueblo. Cuadernos de Pedagogía, 46, 53-55.

Garitano, F. (1972) Ikastolako erlijio arazoaz. Jakin Sorta, 6, 203-218.

Groves, T. (2OIIa) Looking up to Paulo Freire: education and political culture during the Spanish transition to democracy. Paedagogica Historica, 47 (5), 70I-717.

Groves, T. (20Irb) El maestro rural como agente de cultura alternativa durante la Transición española: el caso de la provincia de Salamanca. Aula, Revista de Pedagogía de la Universidad de Salamanca, 17, 133-143.

Groves, T. (20I2) Everyday struggles against Franco's authoritarian legacy: pedagogical social movements and democracy in Spain. Journal of Social History, 46 (2), 305-334.

Haramburu-Altuna, L. (I97i) Pedagogia askatzailea. Gordailu, IO, I5-I8.

Haramburu-Altuna, L. (1972) Ikastola, geroaren habe. Jakin Sorta, 6, I67-184.

J.I. (1982) Gordailu: irakaskuntz kontutan jakintsu eta jator. Argia, 928, 28.03.1982.

Lasa Apalategi, J. (197I) Euskal Erria eta Ikastola (Una polémica en torno a la ikastola). San Sebastián: Edili.

López-GoÑI, I. (2003) Ikastola in the 2oth Century: an Alternative for Schooling in the Basque Country. History of Education, 32, 6, 66I-676.

López-GoÑI, I. (2007) Ikastola: un movimiento popular y pedagógico. Historia de las ikastolas de Navarra. Pamplona: Euskera Kultur Elkargoa.

López-GoÑI, I. (20II) El Movimiento de la Ikastola. Un pueblo en marcha. El modelo ikastola 1960-2010. Bilbao: Euskaltzaindia.

OsA, E. (1972a) Pedagogia eta Gizartea. San Sebastián: Lur.

OsA, E. (1972b) Ikastola eta erlijioa. Jakin Sorta, 6, 185-202.

Ostolaza, M. (20I2) Ikastola. En S. DE PABlo et al. (coords.) Diccionario ilustrado de símbolos del nacionalismo vasco (pp. 493-507). Madrid: Tecnos.

Pozo, M. M. y Braster, J. F. A. (2006) The reinvention of the New Education movement in the Franco Dictatorship (Spain, I936-1976). Paedagogica Historica, 42 (I-2), I09-I26.

Puelles, M. (1999) Educación e ideología en la España contemporánea. Madrid: Tecnos.

Setien, J. F. (1979) Gordailu eta euskal pedagogía. Jakin, II, IO5-IIo.

Sudupe, P. (2013) Eusebio Osa. Belaunaldi baten lekuko. Bilbao: upv/EHu.

Zubiondo, J. y Mollarri, J. (1983) Gizartearen teoria kritikoa interesatzen zait. Argia, 9.10.1983. 